\title{
Serum lipids and mood in working men and women in Sweden
}

\author{
Gunnar Lindberg, Gerry Larsson, Sven Setterlind, Lennart Råstam
}

\begin{abstract}
Study objective - To explore the link between serum cholesterol and suicide by investigating the relation between serum lipids and depressive symptoms.

Design - This was a cross sectional study of the relation between serum cholesterol, low density lipoprotein (LDL) cholesterol, high density lipoprotein (HDL) cholesterol, and triglycerides on the one hand and depressive symptoms as expressed in a questionnaire on the other.

Setting - An organisational development programme in industry with assistance from occupational health care.

Participants - A total of 644 male and 261 female employees (mainly white-collar workers) participated.

Main results - Total cholesterol and LDL cholesterol values were lower in those men who, sometimes, often, or very often, had experienced low mood or glumness during the past month compared with those who had not. Serum triglyceride concentrations did not differ between the groups. In women, however, the serum triglyceride value, but not the total cholesterol or LDL cholesterol, was lower in those who reported low mood, depression, or anxiety during the past six months.

Conclusions - Decreasing appetite as a consequence of depression in men would probably lead to both decreasing cholesterol and triglyceride concentrations. Thus, these data indicate the presence of some other explanation for the relation between the level of LDL cholesterol and depressive symptoms in men.
\end{abstract}

( $(\mathcal{F}$ Epidemiol Community Health 1994;48:360-363)

Centre for Public Health Research, Bealth Research, Karlstad, Sweden $G$ Lindberg

G Larsson

Department of Pedagogics, University of Gothenburg,

Sweden

$S$ Setterlind

Department of Community Health Sciences, Lund

University, Malmö, Sweden

L Råstam

Correspondence to: Dr G Lindberg.

Accepted for publication January 1994
In their meta-analysis of six randomised primary prevention trials, Muldoon et al identified a statistically significant relation between interventions to lower high serum cholesterol concentrations in middle aged men and deaths from accidents, homicide, and suicide. ${ }^{1}$ This relation was seen in diet trials ${ }^{23}$ as well as in drug trials. ${ }^{4-7}$ From these observations one might assume that lowering the cholesterol concentration from an individual's habitual level causes an increased risk of suicide. Assuming a causal relationship, the likely link would include depression or, as suggested by Engelberg, ${ }^{8}$ poorer suppression of aggressive behaviour induced by changed intracerebral cholesterol homoeostasis.

Muldoon's analysis led us to test the hypothesis that the serum cholesterol concentration is negatively related to deaths from accidents and suicide in a general population of both men and women. ${ }^{9}$ In our cohort study, the risk associated with low serum cholesterol (the lower $25 \%$ of the distribution with the upper $25 \%$ used as a reference) for deaths from all injuries including suicide was significantly increased in men during the first seven years of follow up after the estimation of the serum cholesterol concentration (relative risk: 2.8). When suicides only were considered, the relative risk was $4 \cdot 2$.

This study aimed to explore further the link between a low serum cholesterol value and suicide by investigating the relation between serum lipids and depressive symptoms in both men and women.

\section{Subjects and methods}

As part of a work-site based organisational development programme, a total of 729 male and 337 female employees responded to two questionnaires which included questions about lifestyles, psychosocial factors, and psychological traits. They also took part in a general health screening conducted by their occupational health service.

In this study, two questionnaire items were used to identify subjects with depressive symptoms, as follows:

Item 1: How often during the past month have you experienced low mood or glumness? ${ }^{10}$

Item 2: How often during the past six months have you experienced low mood, depression or anxiety? ${ }^{11}$

Responses were given in a Likert scale that included five alternatives for item 1 and four for item 2 . In the analyses, the responses were dichotomised so that the answers "never" and "seldom" form one category indicating the lack of depressive symptoms and "sometimes", "often" and "very often" indicating the existence of such problems.

At the physical examination, weight was measured to the nearest $\mathrm{kg}$ and height to the nearest $\mathrm{cm}$. Body mass index was calculated as weight $(\mathrm{kg}) /\left(\right.$ height $^{2}\left(\mathrm{~m}^{2}\right)$. Blood was drawn from an antecubical vein in seated subjects who had fasted overnight and was sent to the chemical laboratory for analysis on an autoanalyser. Total cholesterol and triglyceride concentrations were analysed by direct enzymatic methods, while high density lipoprotein (HDL) cholesterol was analysed after precipitation with phosphotungstic acid-magnesium chloride. Low density lipoprotein (LDL) cholesterol was estimated as: total cholesterol minus HDL cholesterol minus $0.45^{*}$ triglyceride. Self 
reported alcohol consumption (questionnaire) was estimated as grams of 100 per cent alcohol consumed daily. ${ }^{11}$ Smoking habits as grams of tobacco consumed daily were also derived from questionnaire items. ${ }^{11}$

\section{STATISTICAL METHODS}

Differences in means between the subgroups of men and women (separated according to their response to questionnaire items about mood) were tested for statistical significance by Student's $t$ test after adjustment for age by multiple regression analysis. Logarithmic transformation was used when the distribution of a variable (notably the triglyceride concentration and alcohol consumption) was too skewed to fulfil the assumption of normal distribution. $p$ values for trends in lipid concentrations when all four categories of mood were utilised, were estimated by a non-parametric correlation analysis

Table 1 Characteristics of the 644 men and 251 women who were included in the study

\begin{tabular}{|c|c|c|c|c|c|}
\hline \multirow[t]{2}{*}{ Variable } & \multicolumn{2}{|l|}{ Men } & \multicolumn{2}{|l|}{ Women } & \multirow{2}{*}{$\begin{array}{l}\text { p for no } \\
\text { difference }\end{array}$} \\
\hline & Mean & $(S D)$ & Mean & $(S D)$ & \\
\hline $\begin{array}{l}\text { Age (y) } \\
\text { Body mass index }\left(\mathrm{kg} / \mathrm{m}^{2}\right)\end{array}$ & $\begin{array}{l}41 \cdot 1 \\
25.0\end{array}$ & $\begin{array}{l}(10.5) \\
(2.93)\end{array}$ & $\begin{array}{l}38 \cdot 4 \\
23 \cdot 1\end{array}$ & $\begin{array}{l}(11 \cdot 1) \\
(3 \cdot 12)\end{array}$ & $\begin{array}{r}0.001 \\
<0.001\end{array}$ \\
\hline $\begin{array}{l}\text { Total cholesterol (mmol/l) } \\
\text { LDL cholesterol }(\mathrm{mmol} / \mathrm{l}) \\
\text { HDL cholesterol }(\mathrm{mmol} / \mathrm{l}) \\
\text { Triglycerides }(\mathrm{mmol} / \mathrm{l}) \\
\text { Alcohol consumption }(\mathrm{g} / \text { day }) \\
\text { Tobacco consumption }(\mathrm{g} / \text { day })^{*}\end{array}$ & $\begin{array}{l}5 \cdot 72 \\
3 \cdot 76 \\
1 \cdot 35 \\
1 \cdot 36 \\
1 \cdot 12 \\
0 \cdot 77\end{array}$ & $\begin{array}{l}(1 \cdot 12) \\
(1 \cdot 00) \\
(0 \cdot 35) \\
- \\
-\end{array}$ & $\begin{array}{l}5 \cdot 40 \\
3 \cdot 34 \\
1 \cdot 62 \\
0 \cdot 98 \\
0 \cdot 81 \\
0 \cdot 71\end{array}$ & $\begin{array}{l}(1 \cdot 07) \\
(0 \cdot 97) \\
(0 \cdot 38) \\
- \\
-\end{array}$ & $\begin{array}{c}<0.001 \\
<0.001 \\
<0.001 \\
<0.001 \\
<0.001 \\
\quad 0.54\end{array}$ \\
\hline
\end{tabular}

*426 men $(66 \%)$ and 178 women $(61 \%)$ were non-smokers.

Table 2 Age adjusted serum lipid concentrations (mmol/l) by self reported low mood or glumness during the past month

\begin{tabular}{lcccccc}
\hline & \multicolumn{2}{l}{$\begin{array}{l}\text { Never or seldom } \\
\text { low mood }\end{array}$} & \multicolumn{3}{c}{$\begin{array}{l}\text { Sometime, often, or } \\
\text { very often low mood }\end{array}$} & $\begin{array}{c}\text { p for no } \\
\text { difference }\end{array}$ \\
\cline { 2 - 3 } & Mean & $(S D)$ & Mean & $(S D)$ & \\
\hline Men: & $(\mathrm{n}=484)$ & & $(\mathrm{n}=160)$ & & \\
Total cholesterol & 5.80 & $(0.99)$ & 5.50 & $(1.08)$ & 0.002 \\
LDL cholesterol & 3.83 & $(0.91)$ & 3.54 & $(0.91)$ & 0.001 \\
HDL cholesterol & 1.35 & $(0.34)$ & 1.37 & $(0.37)$ & 0.50 \\
Ln triglycerides & 0.169 & $(0.53)$ & 0.117 & $(0.51)$ & 0.27 \\
Women: & $(\mathrm{n}=138)$ & & $(\mathrm{n}=113)$ & & \\
Total cholesterol & 5.32 & $(0.84)$ & 5.45 & $(0.89)$ & 0.22 \\
LDL cholesterol & 3.27 & $(0.79)$ & 3.38 & $(0.85)$ & 0.25 \\
HDL cholesterol & 1.61 & $(0.38)$ & 1.64 & $(0.37)$ & 0.52 \\
Ln triglycerides & -0.140 & $(0.44)$ & -0.173 & $(0.47)$ & 0.58 \\
\hline
\end{tabular}

Table 3 Age adjusted serum lipid concentrations (mmol/l) by self reported low mood, depression, or anxiety during the past six months

\begin{tabular}{|c|c|c|c|c|c|}
\hline & \multicolumn{2}{|c|}{$\begin{array}{l}\text { Never or seldom } \\
\text { low mood }\end{array}$} & \multicolumn{2}{|c|}{$\begin{array}{l}\text { Sometime, often, or } \\
\text { very often low mood }\end{array}$} & \multirow[t]{2}{*}{$\begin{array}{l}\text { p for no } \\
\text { difference }\end{array}$} \\
\hline & Mean & $(S D)$ & Mean & $(S D)$ & \\
\hline $\begin{array}{l}\text { Men: } \\
\text { Total cholesterol } \\
\text { LDL cholesterol } \\
\text { HDL cholesterol } \\
\text { Ln triglycerides }\end{array}$ & $\begin{array}{c}(\mathrm{n}=353) \\
5 \cdot 78 \\
3.83 \\
1.34 \\
0.151\end{array}$ & $\begin{array}{l}(1.02) \\
(0.92) \\
(0.34) \\
(0.53)\end{array}$ & $\begin{array}{c}(n=291) \\
5.65 \\
3.67 \\
1.37 \\
0.161\end{array}$ & $\begin{array}{l}(1 \cdot 02) \\
(0 \cdot 89) \\
(0 \cdot 36) \\
(0.51)\end{array}$ & $\begin{array}{l}0 \cdot 10 \\
0.02 \\
0 \cdot 26 \\
0 \cdot 81\end{array}$ \\
\hline $\begin{array}{l}\text { Women: } \\
\text { Total cholesterol } \\
\text { LDL cholesterol } \\
\text { HDL cholesterol } \\
\text { Ln triglycerides }\end{array}$ & $\begin{array}{c}(n=79) \\
5.50 \\
3.39 \\
1.62 \\
-0.066\end{array}$ & $\begin{array}{l}(0.80) \\
(0.72) \\
(0.37) \\
(0.47)\end{array}$ & $\begin{array}{c}(n=172) \\
5.32 \\
3.29 \\
1.62 \\
-0.196\end{array}$ & $\begin{array}{l}(0.90) \\
(0 \cdot 86) \\
(0.38) \\
(0.44)\end{array}$ & $\begin{array}{l}0.12 \\
0.33 \\
0.94 \\
0.04\end{array}$ \\
\hline
\end{tabular}

(Kendall's tau-b). Relations between serum lipids, age, smoking habits, and alcohol consumption on the one hand and mood on the other were also calculated from a logistic regression model to assess the influence of each independent variable. All tests were two tailed. Statistical significance was assumed at $\mathrm{p}<0.05$.

\section{Results}

A total of 85 men and 86 women were excluded because of incomplete data. Thus, final totals of $644(88 \%)$ men and $251(74 \%)$ women were included in the analyses. The characteristics of the subjects are presented in table 1 . The men were on average older than the women and had higher body mass index, total cholesterol, LDL cholesterol, and triglyceride concentrations, but the women had a higher HDL cholesterol concentration (table 2).

MOOD DURING THE PAST MONTH (ITEM 1)

Men who reported depressive symptoms during the past month had lower age adjusted concentrations of both serum total cholesterol $(5.30 v 5.50 \mathrm{mmol} / \mathrm{l}, \mathrm{p}=0.002)$ and LDL cholesterol $(3.54 v 3.83 \mathrm{mmol} / \mathrm{l}, \mathrm{p}=0.001) \mathrm{com}-$ pared with men who did not, but this difference was not observed in women (table 2). There were significant trends between mood and total cholesterol $(p=0.005)$ as well as LDL cholesterol $(p=0.02)$. No statistically significant differences were seen for serum HDL cholesterol or triglyceride concentrations.

MOOD DURING THE PAST SIX MONTHS (ITEM 2) Men who reported that they had experienced depressive symptoms or anxiety during the past six months had a lower age adjusted concentration of serum LDL cholesterol (3.67 v $3.83 \mathrm{mmol} / \mathrm{l}, \mathrm{p}=0.02$, $\mathrm{p}$ for trend $=0.03$ ) compared with men who did not (table 3 ). The female, age adjusted serum triglyceride concentration was related to mood, with a lower mean in women who had experienced depressive symptoms or anxiety during the past half year compared with women who had not (table 3). However, the trend was not significant.

\section{ITEMS 1 AND 2 COMBINED}

In total, 146 men stated that they had experienced low mood sometimes, often, or very often during the past month, as well as during the past six months. Their age adjusted total cholesterol and LDL cholesterol values were not significantly different from the concentrations in all 160 men who had experienced low mood during the past month. Nor did the differences in their serum total cholesterol and LDL cholesterol values, compared with 339 men who had never or seldom experienced depressive symptoms during the past month or during the past six months, diverge from the differences when only mood during the past month was taken into consideration $(0.28 v$ $0.30 \mathrm{mmol} / 1$ for total cholesterol and $0.29 v$ $0.29 \mathrm{mmol} / 1$ for LDL cholesterol respectively). 


\section{LOGISTIC REGRESSION}

Logistic regression was used to test for confounding from body mass index, smoking habits, and alcohol consumption in the above age only adjusted relationships. The results were not changed after this procedure, leaving total cholesterol and LDL cholesterol values in men and triglycerides in women as the only lipid fractions significantly related to mood. The results when mood during the past month was used as the dependent variable and LDL cholesterol entered as independent variable are shown in table 4.

\section{Discussion}

In this study we found a relation between $\mathrm{LDL}$ cholesterol and depressive mood in men but not in women. The results are consistent with our earlier reported higher mortality from suicide in men (but not in women) with a low serum cholesterol concentration. ${ }^{9}$ In contrast, we found a relation between low mood and a low serum triglyceride concentration in women, but this was confined only to depressive symptoms or anxiety during the past six months.

It should be noted that the data for this study were not originally collected to test the hypothesis under consideration. The face validity of the two items on depressive symptoms has therefore to be accepted. In addition, we have to consider how representative the subjects were. They were not drawn from a general population, but instead their selection was based upon employment status. Most were white collar workers, and thus the social span was narrow. On the other hand, this study involved younger subjects than previous ones, and both men and women, enabling us to draw conclusions about values in premenopausal women.

Results published by other authors on this topic are inconsistent. Morgan et al found that depression was three times more common in male Californians aged 70-89 years with a low plasma cholesterol concentration. ${ }^{12}$ While they also reported a negative trend between depressive symptom scores and plasma cholesterol concentration in men aged 80-89 years, no such relationship was shown in men younger than 70 years. In neither male nor female French volunteers aged 60-69 years was there any linear

Table 4 Relations between LDL cholesterol and possible confounders with self reported low mood, depression, or anxiety during the past month in 644 men and 251 women calculated by logistic regression analysis

\begin{tabular}{lrl} 
& B-coefficient & $p$ \\
\hline Men: & & \\
LDL cholesterol (mmol/l) & -0.3344 & 0.001 \\
Age (y) & 0.0072 & $0 \cdot 47$ \\
Body mass index $\left(\mathrm{kg} / \mathrm{m}^{2}\right)$ & $0 \cdot 0083$ & $0 \cdot 80$ \\
Smoking (no/yes) & $-0 \cdot 1082$ & $0 \cdot 28$ \\
Ln alcohol consumption (g/d) & $-0 \cdot 1490$ & $0 \cdot 15$ \\
Women: & & \\
LDL cholesterol (mmol/l) & $0 \cdot 1685$ & 0.32 \\
Age (y) & -0.0081 & 0.57 \\
Body mass index $\left(\mathrm{kg} / \mathrm{m}^{2}\right)$ & 0.0275 & 0.56 \\
Smoking (no/yes) & $-0 \cdot 1647$ & $0 \cdot 26$ \\
Ln alcohol consumption (g/d) & $0 \cdot 1808$ & $0 \cdot 17$ \\
\hline
\end{tabular}

correlation between serum total cholesterol and self reported symptoms of depression. ${ }^{13}$ These symptoms were, however, significantly more common in both men and women who had a cholesterol concentration in the lowest quintile compared with all others. In a Finnish study, Strandberg et al failed to show such a relationship in either men or women aged 75-85 years. ${ }^{14}$

From the Whitehall II study cohort of middle aged male and female civil servants, Brunner et al reported no difference in the mean serum cholesterol in subjects with and without minor psychiatric disorders including neurotic depression, anxiety states, and obsessional neurosis. ${ }^{15}$ In a study by Benton and Fordy, seven women with a serum cholesterol value below $3.2 \mathrm{mmol} / \mathrm{l}$ had significantly high scores for psychiatric problems. ${ }^{16}$ However, neither of these two studies aimed specifically to investigate depressive symptoms.

No a priori conclusions can be drawn from our data about causal relationships. Decreased appetite and weight loss in depressed subjects may underlie the relationship between low cholesterol and depressive symptoms. ${ }^{17}$ It has also been suggested that illness that causes weight loss and depression may be followed by a reduced plasma cholesterol concentration. ${ }^{17}$ When the loss of appetite and weight loss causes a decreased cholesterol concentration, however, one would also expect to find a low serum triglyceride value. Thus, it is unlikely that the lower LDL cholesterol levels in depressed men are caused by loss of appetite or weight loss. Furthermore, adjustment for body mass index did not influence the relation between LDL cholesterol and mood in men. Our data also failed to show any influence of alcohol consumption and smoking habits on the relationship between serum lipids and low mood. Thus, excessive drinking or smoking in subjects with low mood are unlikely to explain the findings.

The obvious discrepancies in the relation between cholesterol and mood found when comparing men with women and when comparing postmenopausal women (significant relation $)^{13}$ with those in the present study who were mainly premenopausal (no relation), support the suggestion that lowering of the cholesterol concentration is a cause of low mood. Hormonal status may be linked to the intracerebral cholesterol concentration. ${ }^{18}$ The consistency of our data and previous publications indicate that the risk is modified by hormonal status with a pattern inverse to that of high cholesterol level as a cause of myocardial infarction. Another possible interpretation could be that mood alterations influence the serum lipid concentrations in one way in men and in older women and in another way in younger women.

The weaker correlation between total cholesterol (and LDL cholesterol) and frequency of low mood during the past six months (item 2), indicates a narrow temporal relation between changes in the cholesterol concentration and changes in mood in men. Decision about causality, however, warrants a prospective study design. 
1 Muldoon MF, Manuck SB, Mathews KA. Lowering cholesterol concentrations and mortality: a quantitative review of primary prevention and mortality: a quantitative revic

2 Dayton S, Pearce ML, Hashmoto S, Dixon WJ, Tomiyasu U. A controlled clinical trial of a diet high in unsaturated fat in preventing complications of atherosclerosis. Circulation 1969;39-40(suppl II):1-63.

3 Frantz ID, Dawson EA, Ashman PL, et al. Test of effect of lipid lowering by diet on cardiovascular risk. Arteriosclerosis 1989;9:129-35.

4 Committee of Principal Investigators. A co-operative trial in the primary prevention of ischaemic heart disease using clofibrate. Br Heart $\mathcal{F}$ 1978;40:1069-118.

5 Dorr AE, Gundersen K, Schneider JC, Spencer TW, Martin WB. Colestipol hydrochloride in hypercholesterolaemic patients - effect on serum cholesterol and mortality. $\mathcal{f}$ patients - effect on serum

6 Lipid Research Clinics Program. The Lipid Research Clinics coronary primary prevention trial results. $\mathfrak{f} A M A$ coronary primary

7 Frick MH, Elo O, Haapa $\mathrm{K}$, et al. Helsinki heart study: primary-prevention trial with gemfibrozil in middle-aged men with dyslipidemia. $N$ Engl f Med 1987;317:1237-45.

8 Engelberg G. Low serum cholesterol and suicide. Lancet 1982;339:727-9.
9 Lindberg G, Råstam L, Gullberg B, Eklund GA. Low serum cholesterol concentration and short term mortality from injuries in men and women. BMF 1992;305:277-9.

10 Larsson G, Setterlind S. A stress reduction program led by health care personnel: Effects on health and well-being. Eur f Public Health 1991;1:90-3.

11 Setterlind S, Larsson G. The stress profile: A psychosocia tool for change. Arbete, Människa, Miljö 1990;1:44-50. (In Swedish)

12 Morgan RE, Palinkas LA, Barrett-Connor EL, Wingard DL. Plasma cholesterol and depressive symptoms in older men. Lancet 1993;341:75-9.

13 Dealberto MJ, Ducimetiere P, Mainard F, Alperovitch A Serum lipids and depression. Lancet 1993;341:435.

14 Strandberg TE, Valvanne J, Tilvis RS. Serum lipids and depression. Lancet 1993;341:433-4.

15 depression. Lancet 1993;341:433-4. serum cholesterol and suicide. Lancet 1992;339:1001-2.

16 Benton D, Fordy J. Low serum cholesterol and violent death. BMF 1992;305:772-3.

17 Davey Smith G, Shipley MJ. Serum lipids and depression. Lancet 1993;341:433-4.

18 Baulieu E-E, Robel P. Neurosteroids: A new brain function? f Steroid Biochem Molec Biol 1990;37:395-403. 